\title{
MEMÓRIA E HISTÓRIA DE MULHERES: UMA BIBLIOTECA FEMINISTA
}

\author{
Mary Lucy Murray Del Priore \\ Depto. de História-FFLCH/USP
}

Historiadores, interessados em assuntos, memória temas e bibliografia sobre a história do gênero, da mulher ou da condição feminina, têm, agora, endereço certo para suas pesquisas. Trata-se da Biblioteca Marguerite Durand, em Paris. Criada há sessenta anos, é a primeira biblioteca de documentação feminista, criada por uma feminista de renome internacional - a própria Marguerite Durand - que em 1931 doou à prefeitura da cidade a coleção de documentos e livros reunidos ao longo de sua vida.

Mas quem foi esta personagem histórica? MargueriteCharlotte Durand nasceu em 24 de janeiro de 1864 e seus documentos declaravam-na filha de pai desconhecido. Sua mãe, contudo, nascida no interior de uma família de eruditos, criara-se no palácio imperial russo onde era a leitora da grã-duquesa Helena e autora de um "Dicionário de Mulheres Célebres", jamais publicado. Seu avô, fora amigo e advogado de Benjamim Constant e o primeiro tradutor de Schiller para o francês. Embora não tenha sido reconhecida oficialmente por seu pai, sabe-se que esse era o coronel Alfred Bocher, um "royaliste", personagem importante de campanhas militares na Criméia, Itália e México.
Marguerite recebeu a educação religiosa tradicional das jovens burguesas de sua época; ela freqüentou o convento das Damas Trinitárias cujos ensinamentos e ideais convinham mal a uma jovem que, muito cedo, optou pela carreira teatral. Em 1881 já entrava na Comédie Française onde procurava encenar peças de gosto feminista. Em 1891, depois de divorciar-se do marido, um político que a introduziu ao jornalismo, Marguerite passou a colaborar para o Le Fígaro, no qual animava um correio de leitores. Em 1896, depois do nascimento de Jacques, seu filho natural com o famoso jornalista Antonin Périvier, Marguerite é encarregada de cobrir aquele que foi o evento do ano: o congresso feminista internacional, organizado pela Liga Francesa pelos Direitos da Mulher. O congresso, presidido por Maria Pognon, feminista, livre pensadora e membro da maçonaria, conheceu acaloradas discussões: os estudantes socialistas acusavam as congressistas de "burguesas exploradoras". Maria Pognon retrucava afirmando que as operárias não poderiam adquirir direitos econômicos se as burguesas não metessem as mãos "na massa"! Defendendo a solidariedade do sexo e recusan- 
do a luta de classes dentro do feminismo, ela se opunha firmemente à idéia de que apenas a via socialista permitiria a libertação das mulheres. O congresso de 1896 foi uma verdadeira revelação para Marguerite. Convertida ao feminismo, ela tornou-se, rapidamente, uma militante: "Meditar sobre a justeza dessas reivindicações - escreve ela em 1902 - e considerar um dever social o auxílio ao triunfo de suas idéias, eis o que me levou a conceber um grande jornal feminista onde, quotidianamente, as mulheres possam defender os interesses das mulheres". Foi assim que, em 1897 nasceu La Fronde, um jornal único na história da imprensa, inteiramente redigido, composto, administrado e dirigido por mulheres. Aí trabalharam Séverine, filha espiritual de Jules Vallès, defensora renhida dos pobres e oprimidos; Madame Vincent, criadora da Sociedade para a reivindicação dos Direitos da Mulher e fundadora de um "feminismo histórico" baseado em pesquisas que buscavam, nos documentos, provar a hegemonia do poder feminino no passado; Nelly Roussel, socialista e partidária de Dreyfus, defensora da "livre maternidade" contra a "maternidade sem consentimento" e dos salários femininos, condição essencial de independência da mulher; Maria Vérone, advogada e importante personalidade feminista do período entre guerras; Avril de Sainte-Croix, autora de inúmeros artigos sobre a condição das prisões femininas, o alcoolismo feminino, a prostituição; esses, entre outros grandes nomes de feministas ou de anônimas que colocaram seu talento a serviço do jornal. Algumas campanhas do jornal foram tão bem sucedidas que permitiram às mulheres a admissão à Escola de Belas Artes, assistir aos debates parlamentares, receber a Légion d'Honneur, aceder aos tribunais etc.

Outra iniciativa de La Fronde foi a realização, em plena Exposição Universal de Paris, entre 5 e 8 de setembro de 1900, de um congresso internacional dos Direitos da Mulher. Além do congresso, uma exposição feminista destinada a atrair os milhares de visi- tantes da Exposição, foi, também, montada. Primeira no gênero, essa exposição reuniu cinco sociedades feministas que expuseram retratos e fotografias de militantes vivas ou mortas, livros, revistas e brochuras. Madame Vincent apresentou os arquivos que organizara com documentos relativos ao papel e à história das mulheres; podia-se, ainda, consultar painéis com estatísticas e informações relativos às diferentes associações. O congresso conheceu, segundo a crônica de época, um retumbante sucesso.

Marguerite Durand continuou sua carreira de jornalista criando o anti-clerical e socialista L'Action, em 1905 e depois, Les Nouvelles em 1909, esse último de nítido caráter financeiro. Em 1907, ela dirigiu um congresso tendo em vista a criação de um Ofício do Trabalho da Mulher. Um ano mais tarde, lançou a idéia de organizar candidaturas femininas às eleições legislativas apresentando-se como deputada. Em 1921, sempre incansável, formalizou novamente sua candidatura, agora no seio do partido republicano-socialista. Ao longo de sua vida, interessou-se pela sorte de empregados e operários, criando inúmeros sindicatos, entre outros, o das mulheres tipógrafas.

Generosa, apaixonada, ambiciosa, bela e muito elegante, Marguerite Durand teve, segundo seus biógrafos ${ }^{1}$, uma vida "iluminada". Grande figura do feminismo de seu tempo, preocupou-se em coletar, reunir e conservar os arquivos e documentos relativos à

\footnotetext{
${ }^{1}$ A bibliografia sobre Marguerite Durand é extensa. Vale começar por Annie Didier-Metz e seu La Bibliothèque Marguerite Durand: histoire d'une femme, mémoire des femmes, Paris, Mairie de Paris, 1992, a quem emprestei várias das informações aqui reproduzidas. Ver também Sue Helder Goliber, The life and Times of Marguerite Durand, tese PHD, Kent State University, 1975; Huas, Jeanine, Sur les traces du tigre, Paris, Lachuré, 1987, J. Mermeix, Les coulisses du boulangisme, Paris, Cerf, 1890; Jean Rabaud, Marguerite Durand (1864-1936): La Fronde féministe ou Le temps en jupons, Paris, L”Harmattan, 1996.
} 
história das mulheres e seu papel na sociedade e em todos os domínios de suas atividades. Em 1931 ela doou à cidade de Paris o conjunto de suas coleções, criando a primeira biblioteca feminista francesa oficial. Ela a dirigiu até sua morte, aos 76 anos, à 16 de março de 1936.

Depois da mulher, a biblioteca. Essa reunia, na época de sua fundação, 10.000 volumes e vários milhares de brochuras. A reprodução integral da doação original permite uma descrição aproximada de seu acervo:

"Conjunto importante de obras, documentos, retratos, autógrafos relativos à condição das mulheres através dos tempos.

Coleção de decretos, leis, regulamentos especiais sobre mulheres.

Coleção de jornais e cartazes feministas, de fichas relativas à bibliotecas e museus.

Obras tratando da condição legal ou social das mulheres, 3.000 volumes.

Obras de teorias feministas ou anti-feministas antigas e modernas, 2.000 volumes (igual número de brochuras sobre o mesmo tema).

As mulheres em todos os domínios de atividade social: mulheres científicas, políticas, artistas, literárias, professoras, advogadas, médicas, dentistas, funcionárias etc., aproximadamente 2.000 volumes.

Coleção (rara) de teses de doutoramento apresentadas por mulheres ou relativas à questões da mulher, 300 volumes.

Memórias históricas, lembranças escritas por mulheres ou relativas às mulheres, cerca de 500 volumes.

História e atos de rainhas e regentes, obras e instituições femininas, direito da mulher, sufrágio feminino, educação, ensino, etc., 200 volumes

Ordens religiosas femininas: educadoras, missionárias, contemplativas, suas fundadoras, as grandes abadessas, etc., 200 volumes.

Obras e associações de caridade: sindicatos femininos, publicações do Ministério do Trabalho, leis e decretos sobre o trabalho feminino, 500 volumes

Sociedades feministas novas e antigas: históricos, fundadoras, atividades, boletins, publicações, reuniões (documentação em dia), volumes e brochuras, retratos, autógrafos antigos e moder- nos, fichas das principais bibliotecas contendo documentos sobre questões feministas e sobre militantes feministas.

História de Paris: prisões, conventos, casas célebres, planos de higienização.

Obras de interesse geral; dicionários históricos, franceses e estrangeiros, revoluções de Paris, dossiers, artigos de imprensa, dossiers sobre personalidades femininas importantes.

Coleção de jornais feministas antigos e modernos, cartazes, boletins, etc.

Documentação sobre carreiras acessíveis às mulheres desde a segunda metade do século XIX: médicas, advogadas, farmacêuticas, dentistas, engenheiras, etc.

Mulheres vencedoras de prêmios, conquistas femininas: histórico, resultados.

Volumes encadernados ou não ou brochuras sobre novas atividades femininas: superintendência de fábricas, enfermeiras escolares, etc., quantidades não negligenciáveis".

A biblioteca possui uma vocação enciclopédica sobre tudo o que diz respeito às mulheres e não parou de crescer desde sua fundação. Calcula-se, hoje, possuir um acervo em torno de 25.000 volumes. Na chamada "Réserve" encontram-se obras raras. Aí contam-se dois títulos do século XVI, vinte e dois, do século XVII, cento e cinqüenta e um dos século XVIII e cento e vinte e cinco da primeira metade do século XIX. Um estudo temático, segundo Annie Didier-Metz ${ }^{2}$, revelou uma grande incidência de livros sobre história e política, seguidos por literatura e feminismo. É bom lembrar que o termo surgiu no século XIX e tinha sentido muito amplo. Estão igualmente bem representadas as memórias e biografias, as obras que se referem ao casamento, ao amor e à sexualidade, bem quanto à religião.

Alguns volumes merecem ser citados por sua raridade; é o caso, por exemplo, de Galerie des femmes fortes, da autoria do padre Pierre Lemoyne, editado em 1654, consagrado às mulheres célebres

\footnotetext{
${ }^{2}$ Op.cit., pp.42 e passim.
} 
da mitologia, da Bíblia e da História. O grande in folio comporta numerosas e belíssimas gravuras, Ou de E. de Beaumont, les Vésuviennes ou les soldats pour rire, de 1848, obra satírica sobre uma tropa militar de mulheres, organizada pelo governo provisório de 1848 , ricamente ilustrado com gravuras coloridas. A "Réserve" possui, ainda, edições originais de numerosas escritoras como Mlle. De Scudéry, Mme. De Genlis, Mme. De Staël, Olympe de Goujes ou Mary Wollstonecraft, bem como inúmeros tratados de defesa das mulheres, muitas vezes anônimos, como é o caso do L'Apothéose du beau sexe (1722) ou Apologie des Dames (1737). A biblioteca conta com todos os textos escritos por feministas, base indispensável de todo o estudo sobre o assunto. Mas conta, também, com um imenso número de obras de literatura escritas por mulheres, de George Sand à Colette, ou à escritores consideradas "menores" pela crítica: Myriam Harry ou Renée Vivien entre outras.

Na parte de periódicos, a biblioteca é constituída de publicações exclusivamente feministas ou femininas, reunindo um total de 936 títulos, essencialmente da segunda metade do século XIX e XX, dos quais a metade é em língua francesa. Entre os mais conhecidos figuram o já mencionado La Fronde, La Citoyenne, fundado em 1881, La suffragiste de 1908 ou o Journal des Dames de 1759. As revistas contemporâneas são extremamente atualizadas e aí podemos encontrar exemplares de Signs, editada nos EUA, Feminist Review, na Inglaterra, Feministische Studies, na Alemanha, Cahiers du GRIEF, publicação franco-belga, Australian feminist studies, entre outros.

Os dossiers biográficos - cerca de 400 - constituem a parte mais rica da biblioteca. Compostos por recortes de jornais e de revistas, por resenhas, por deliberações jurídicas, por folhetos de cordel, por panfletos distribuídos quando de greves, manifestações e etc., por cartões de convite e agradecimento, agru- pam uma volumosa "ephemera" capaz de dar conta de testemunhos diretos e vivos de tudo quanto era relativo aos movimentos feministas históricos ou contemporâneos. Os dossiers contém ainda documentos manuscritos e autógrafos.

A biblioteca conta ainda com cerca de 200 coleções de manuscritos e 400 cartas autografadas. As primeiras são constituídas por textos de ficção e documentários diversos; vemos aí desde novelas à peças de teatro, passando por conferências e discursos, aulas e palestras até agendas pessoais. As cartas mais antigas são do punho de Marie de Cléves, datada de 1468 e de Santa Catarina de Ricci, de 1522. A coleção de cartões postais monta a 3000 unidades. As coleções de cartazes e retratos ilustram, cada vez mais, teses e livros atualmente publicados. Os documentos iconográficos incidem particularmente sobre os retratos de mulheres famosas, os trabalhos femininos tradicionais, roupas e moda, costumes regionais, caricaturas, casas de mulheres célebres. Entre as 3000 fotografias do acervo há várias sobre reuniões feministas ou "etno-fotografias" tiradas no início do século em vários países do mundo, apresentando mulheres e seus costumes. Os autores das fotos são nomes do porte de Aline Lang, Denise Colomb, Jaime Abecassis e outros. Há, ainda, no setor iconográfico, uma coleção de cerca de 1000 cartazes, sendo que os mais antigos datam de 1792, - há um belíssimo sobre Olympe de Goujes e outro sobre a Comuna de Paris. O grosso da coleção cobre os anos 1910-1945.

Não é possível resumir todos os campos cobertos pela enorme variedade de livros e brochuras: filosofia, religião, direito, política, educação, ciências, música (inclusive partituras musicais impressas por compositoras), artes plásticas. A atual política de aquisições contempla obras publicadas nos Estados Unidos da América, Espanha, Itália, Alemanha e Portugal. 
A biblioteca localizada no número 79 da rue Nationale, está aberta ao público vinte horas por semana, de terças feiras aos sábados. A recepção é extremamente gentil e qualquer pesquisador brasileiro será muito bem vindo. Vale lembrar que a direção fica muito grata às doações feitas por historiadores brasileiros a respeito de suas próprias pesquisas ou de pesquisas feitas no Brasil. O assunto que lhes interessa, contudo, é só um: mulher!
L'hebdomadaire "La Française" fut fondé par la féministe Jane Mise (1865-1935) en octobre 1906 et parut jusqu'en 1940. Bibliothèque Marguerite Durand.
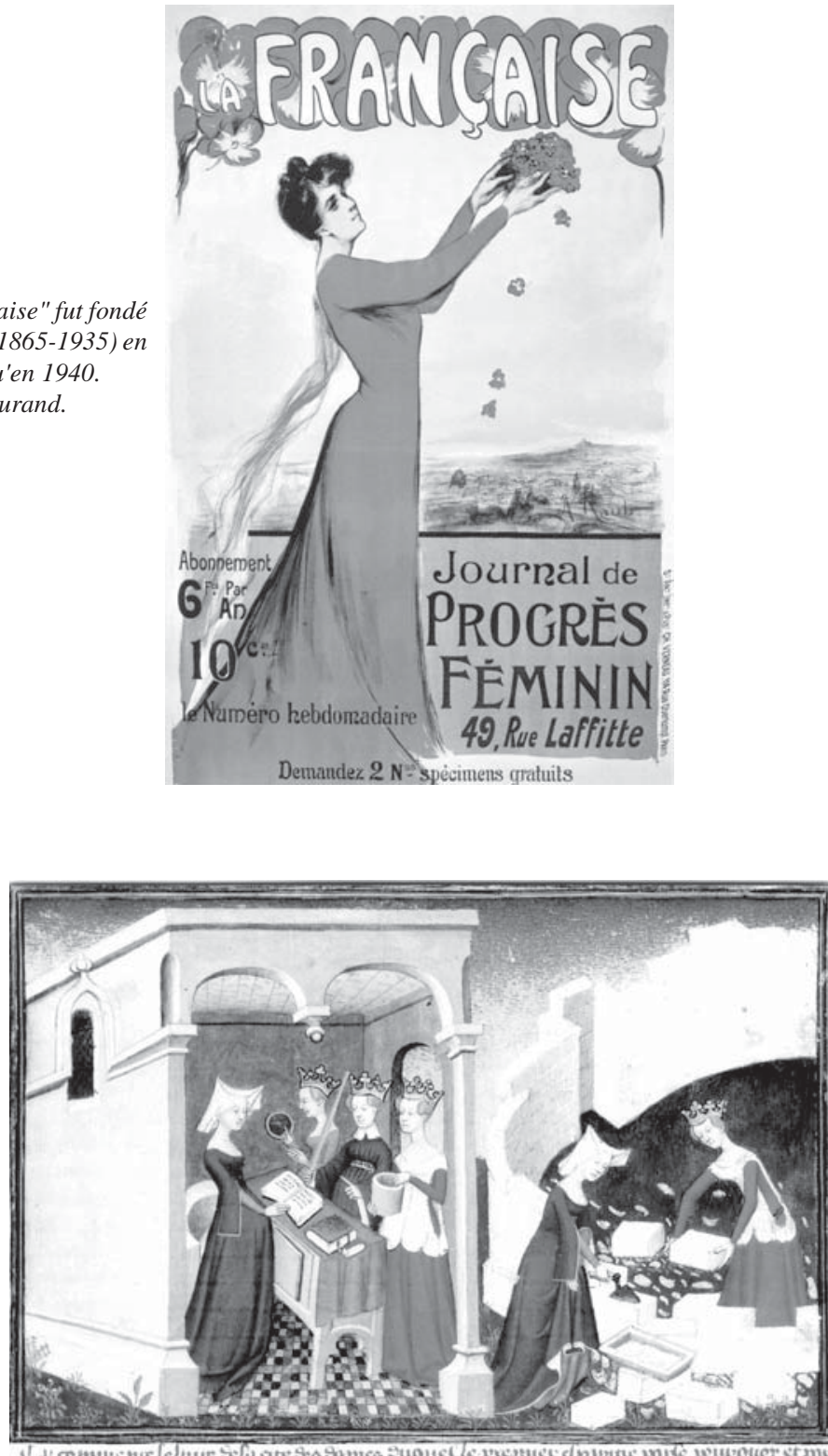

Apparition de Raison, Droiture et Justice à Christine de Pisan. Construction de la Cité des Dames, "Christine de Pisan, La Cité des Dames". Exemplaire de Jean de Berry, enluminé par le Maître de la Cité des Dames, vers 1405. Bibliothèque nationale de France. 